\title{
8
}

\section{Gastrointestinal Status and}

\section{Microbiota Shaping in Amyotrophic Lateral Sclerosis: A New Frontier for Targeting?}

\author{
Letizia Mazzini ${ }^{1}$ • Fabiola De Marchi ${ }^{1}$ • Elena Niccolai ${ }^{2} \bullet$
} Jessica Mandrioli ${ }^{3}$, Amedeo Amedei ${ }^{2}$

${ }^{1}$ ALS Centre, Department of Neurology, Maggiore della Carità Hospital, University of Piemonte Orientale, Novara, Italy; ${ }^{2}$ Department of Experimental and clinical Medicine, University of Florence, Firenze, Italy; ${ }^{3}$ Department of Biomedical, Metabolic and Neural Science, University of Modena and Reggio Emilia, Modena, Italy

Author for correspondence: Letizia Mazzini, ALS Centre, Department of Neurology, Maggiore della Carità Hospital, University of Piemonte Orientale, Novara, Italy. Email: letizia.mazzini@uniupo.it

Doi: https://doi.org/10.36255/exonpublications.amyotrophiclateralsclerosis. microbiota.2021

\begin{abstract}
Amyotrophic lateral sclerosis (ALS) is a rare and severe neurodegenerative disease affecting the upper and lower motor neurons, causing diffuse muscle paralysis. Etiology and pathogenesis remain largely unclear, but several environmental, genetic, and molecular factors are thought to be involved in the disease process. Emerging data identify a relationship between gut microbiota dysbiosis and neurodegenerative diseases, such as Parkinson's disease, Alzheimer's disease, and ALS. In these disorders, neuroinflammation is being increasingly recognized as a driver for disease onset and progression. Gut bacteria play a crucial role in
\end{abstract}

In: Amyotrophic Lateral Sclerosis. Araki T (Editor), Exon Publications, Brisbane, Australia. ISBN: 978-0-6450017-7-8. Doi: https://doi.org/10.36255/exonpublications. amyotrophiclateralsclerosis.2021

Copyright: The Authors.

License: This open access article is licenced under Creative Commons Attribution-NonCommercial 4.0 International (CC BY-NC 4.0) https://creativecommons.org/licenses/by-nc/4.0/ 
maintaining and regulating the immune system, and changes in gut microbial composition can influence neural function by affecting neuro-immune interactions, synaptic plasticity, myelination, and skeletal muscle function. This chapter outlines the relationship between ALS and the human microbiota, discussing whether an imbalance in intestinal microbiota composition through a pro-inflammatory dysbiosis promotes a systemic immune/inflammatory response, and has a role in ALS pathogenesis, clinical features, progression, and outcome.

Keywords: amyotrophic lateral sclerosis; gut-brain-axis; microbiota; neuroinflammation; neurodegeneration

\section{INTRODUCTION}

The cause of amyotrophic lateral sclerosis (ALS) remains unknown for most patients. An increasing number of susceptibility genes has been recently reported (https://alsod.ac.uk [accessed on 17 June 2021]), but these account for only $10-15 \%$ of all cases. Most often, ALS has a sporadic nature, and the onset is the final result of a combination of genetic and environmental factors. The latter include occupational exposure to toxic substances, viral infections, lifestyle habits, habitual diet, and body mass index. However, contrasting results have been reported regarding environmental elements as being risk factors for disease progression (1).

The study of various dietary risk factors is a fascinating topic, but data retrieved from these studies are hard to measure and standardize. A recent Italian study (2), showed that some foods and nutrients, including red and pork meat, proteins, sodium, and glutamic acid, may be risk factors for ALS, while others such as coffee and tea, bread, and raw vegetables can act as protective factors. It has been reported that a higher ALS risk is associated with increased dietary uptake of fat and glutamate (3). Likewise, in the past decades, the imbalance of gut microbiota (GM) has emerged as a new player connected to the diet-linking the type of diet with the potential of developing ALS. Similarly, all reported environmental factors could theoretically impact GM and its functions. This chapter focuses on GM and its potential imbalance as a risk factor for ALS, highlighting the gastrointestinal and metabolic dysfunction, the gut microbiome changes in motoneuron diseases, the possible clinical correlations, and lastly, the potential therapeutic approaches.

\section{THE MICROBIOTA BRAIN-GUT AXIS}

The GM is a complex population of microorganisms residing in the intestine, with the highest concentration in the colon (4). Diet is a significant factor influencing microbiota in terms of composition and function. The GM changes throughout various life phases, starting relatively simple, and increasing in complexity based on various environmental and physiological influences (e.g., geographic location, race, hormones, nutrition, diet, lifestyle). The GM includes hundreds of bacterial 
species, divided into six phyla: Firmicutes, Bacteroidetes, Proteobacteria, Actinobacteria, Verrucomicrobia, and Fusobacteria. Viruses, protozoa, archaea, and fungi are also involved in this environment.

The GM has multiple functions. First, it constitutes the intestinal barrier, promotes itself, stimulates intestinal epithelial cell regeneration, produces mucus, and feeds the mucosa by producing short-chain fatty acids (SCFAs). GM is involved in the maturation of the immune system in childhood, maturation of intestinal lymphoid tissue, development of effective mechanism against pathogens, stimulation of the acquired immune system, intestinal synthesis and metabolism of certain nutrients, inhibition of growth of pathogenic microorganisms, and detoxification of drugs (5). The GM can communicate with the central nervous system (CNS) through the gut-brain axis (GBA), which is a bidirectional communication between the central and the enteric nervous system, linking the brain's higher-order capacities with peripheral intestinal functions $(6,7)$. Based on these anatomical backgrounds, for the first time, in 2013, the National Institute of Mental Health, USA, launched a project on exploring the mechanisms involved in gut microbiota-brain communication to develop new medications or noninvasive treatments for mental diseases. Since then, studies on the GM's influence on the brain have been increasing, and the gut microbiota-brain axis has become one of the focuses of neurosciences.

\section{ALS AND GASTROINTESTINAL SYMPTOMS}

ALS patients may present a wide range of gastroenteric symptoms and other autonomic and non-motor symptoms. Among these, sialorrhea is a well-known and disabling manifestation that may affect up to $50 \%$ of patients during the disease course (8). Sialorrhea may be associated with mucous secretions and saliva and an impairment of the ability to swallow secretions, but not due to an increase in saliva production. Tongue spasticity, orofacial and palatino-lingual muscle control failure, facial muscular weakness, and an inability to maintain oral and buccal competence contribute to sialorrhea (9). Sialorrhea can cause skin maceration, worsening of dysarthria, psychological stress, social embarrassment, and worsening of quality of life. Furthermore, throat and bronchial secretion and ineffective cough may impair non-invasive ventilation and may increase the risk of aspiration pneumonia (10), representing a frequent cause of death in ALS (11). Treatment of sialorrhea can include medical interventions like anticholinergics and the tricyclic antidepressant amitriptyline, which is effective in about $70 \%$ of patients with mild to moderate sialorrhea. If those treatments are ineffective or scarcely tolerated, more invasive therapy with botulinum toxin A, $\mathrm{B}$, and radiotherapy may be an option (12). Physiologically $1-1.5$ liters/day of saliva are produced, constituted by water, electrolytes, antimicrobials, enzymes, and growth factors. Since salivation facilitates mastication, deglutition, and the beginning of digestion and protects the oral mucosa and teeth, a relationship between oral microbiota composition and sialorrhea may be hypothesized, but this is an unexplored field. Similarly, no studies explore why some patients are unresponsive to treatment than others and the possible role of microbiota on this topic. 
Concerning intestinal symptoms, constipation has been reported in up to half of ALS patients during the disease course, while stool incontinence is a rare finding (13). Previous studies have also reported delayed colonic transit time and gastric emptying in ALS patients $(14,15)$. Some factors such as decreased fluid intake due to dysphagia, dietary changes, medications, lack of physical exercise, motor impairment, and psychological stress have to be considered, but an autonomic involvement cannot be ruled out as well (16). Changes in the intermediolateral columns and the Onuf nucleus in ALS have been detected, which could provide an anatomical explanation for these clinical manifestations, as the enteric nervous system and smooth muscle automatism may be unable to modulate the motor functions of the digestive tract (15). Furthermore, roles for the microbiome in luminal fluid, bile acid metabolism (17), generation of SCFAs (18), methane production (19), and on the mucosal layer of the colon (20) for the regulation of the absorption of fluids into the bloodstream have been proposed. Correspondingly, the vagal nerve could be a route for GM and brain communication (16). Of note, GM has been found to interact with ENS-vagus nerve pathways (21) because bacterial-derived neurotransmitters and neuropeptides can directly activate myenteric neurons, which, through vagal nerve ascending fibers, deliver nerve inputs to the brain (22).

Dysphagia is highly prevalent in ALS, being present in about one quarter at onset (mainly in the bulbar phenotype) and in more than $80 \%$ of patients during the disease course. Dysphagia is related to tongue atrophy, dysfunction in the closure of the soft palate and the larynx due to the nuclear or supranuclear lesions of the cranial nerves, IX, X, and XII, and diaphragm dysfunction. Dysphagia should be assessed promptly in ALS to prevent complication (aspiration pneumonia, weight loss) and organize proper interventions. Physiological swallowing is a crucial parameter for the proper intake of drugs. Since swallowing problems are often underestimated in ALS patients due to the progressive adaptation to slow deterioration of bulbar function (23), their recognition is an important task in multidisciplinary disease management. Weight loss is strictly related to dysphagia and it is considered a negative prognostic factor for survival, where studies show that patients who had weight loss had a shorter survival time than those who had stable weight (24). High caloric intake and enteral feeding are commonly used to sustain nutrition, but it has not been convincingly shown to improve survival, nutritional outcomes, or quality of life (25). There is no study on the relationship between dysphagia, weight loss, and microbiota composition, although abundances of certain bacterial species (Akkermansia muciniphila and Alistipes obesi) have been reported in lean individuals, and their abundance increased during dieting. These, as well as others (Blautia wexlerae and Bacteroides dorei), were the strongest predictors for weight loss when present in high abundance at baseline in healthy people (26). Also, the effect of percutaneous endoscopic gastrostomy insertion on microbiota is unexplored as the only study nearly approaching this topic established that the insertion sites of these catheters in outpatients were frequently colonized (Candida albicans, Staphylococcus aureus, and Escherichia coli), without clinical consequences, although microbiota composition was not studied (27).

In conclusion, gastrointestinal symptoms are part of the disease symptoms, even if they may be underestimated in ALS. They are of clinical relevance since they may reduce food intake and influence survival and quality of life (28). 


\section{METABOLIC DYSFUNCTION IN ALS}

Energy homeostasis results from a correct balance between caloric intake and energy consumption. In ALS patients, the energy balance can be profoundly altered, resulting in a higher consumption than calorie intake. Indeed, during the disease course, patients tend to lose weight, muscle mass, and fat reserves (29). This condition can be due to direct disease effects, such as dysphagia, loss of appetite, and weakness in the upper limb limiting nutrition autonomy. Furthermore, a second fundamental mechanism is also evident, characterized by increased consumption of energy at rest, due to an increase in basal metabolism and an increased resting energy expenditure (REE). This "hypermetabolic state" can be present in about $50 \%$ of sporadic ALS cases (30), while it is higher in familial forms (31). Hypermetabolic patients with ALS have a greater level of lower motor neuron involvement, faster functional decline, and shorter survival; despite this, body weight and BMI changes did not differ between hypermetabolic and normometabolic patients with ALS.

Skeletal muscles have been proposed as a site of origin of this alteration. Some studies have shown that chronic denervation in ALS patients results in increased oxygen consumption. In addition, the skeletal muscles' increase in energy demand can lead to a more significant fat mass depletion (32). These findings are supported by the higher prevalence of lower motoneuron involvement in hypermetabolic patients, which also had a high prevalence of spinal onset disease (33). In the terminal stages of the disease, increased metabolism may be due to higher energy consumption by the respiratory muscles (34).

Several studies investigated the role of BMI in disease progression and survival, suggesting that high-energy reserves at onset can mitigate the increased energy demands occurring during the disease course. Two independent studies suggested a high BMI before the disease was related to better functional outcomes, lower incidence of the disease, and reduced mortality rate $(35,36)$. Patients with a BMI between 30 and 35 had been found to have a better survival outcome than those with a BMI out of this range (both higher and lower) during the early stages of the disease (37). For patients with BMI lower than 30, higher initial BMI predicted slower functional decline; on the contrary, for patients with BMI greater than 30, higher initial BMI predicted more rapid decline (35).

\section{Lipids}

Hyperlipidemia is frequently observed in ALS, but the causes are still unclear; this condition could be partly explained by mitochondrial dysfunction (38) and increased food intake. While weight loss and malnutrition are prognostic factors that negatively impact ALS patients' survival, hyperlipidemia is positively correlated with survival. Dupuis et al. discovered that the frequency of hyperlipidemia, as revealed by increased plasma levels of total cholesterol or LDL, was two-fold higher in patients with ALS than in control subjects, demonstrating that abnormally elevated LDL/HDL ratio significantly increased survival by more than 12 months, as if the increased availability of lipids in circulation is a protective factor (39). In line with the hypothesis of a protective role of elevated LDL/HDL ratio, statins have been associated with worse ALS patients' outcomes (40). 
Statins reduce LDL availability for skeletal muscles by inhibiting cholesterol synthesis, leading to reduced muscle nutrients. Statins also reduce insulin resistance, which increases nutrient support for neuromuscular health (39).

\section{Neuroendocrine mechanisms}

Metabolism changes in ALS patients can result from an incorrect response to central and peripheral neuroendocrine mechanisms responsible for the entire body's metabolism (41). The hypothalamus plays an essential role in regulating calorie intake and expenditure; indeed, the hypothalamus is affected by circulating hormones and locally produced neuropeptides are able to mediate appetite and eating behavior. In this regard, a recent study (42) observed severe atrophy of the anterior and posterior parts of the hypothalamus, both in patients with sporadic ALS and symptomatic ALS mutations, unrelated to whole-brain volume atrophy or disease stage. Furthermore, the hypothalamic volume was directly correlated with BMI. For the hypothalamus' physiological role, it has been proposed that its atrophy in ALS patients can cause alterations in food intake, an increase in energy expenditure, and, subsequently, a reduction in BMI.

\section{CHANGES IN GUT MICROBIOME COMPOSITION IN NEURODEGENERATION AND ALS}

ALS is a very complex disease in which many conditions such as infections or antibiotic exposure, dysphagia, food replacement, motor dysfunction, and lack of movements, could impact the microbiome structure (43). Distinct microbial profiles have been found in many neurological disorders in which the modulation of microbiota (with fecal microbiota transplantation or probiotics administration) has proven to affect brain activity and disease progression (44-46). Evidence linking GM and ALS, collected in animal models and humans, indicate a distinct microbial signature in ALS. The first substantial proof came from the mutant superoxide dismutase $\mathrm{SOD} 1^{\mathrm{G} 93 \mathrm{~A}}$ mouse model, which exhibits a leaky gut, an increased number of abnormal intestinal Paneth cells, and altered microbial communities with reduced levels of butyrate-producing bacteria (47). Interestingly, intestinal dysbiosis was identified in SOD1 ${ }^{\mathrm{G} 93 \mathrm{~A}}$ mice well before the onset of motor dysfunction and immune cell activation (48). Zhang et al. demonstrated that mice treated with butyrate restored intestinal microbial homeostasis and decelerated ALS progression (49). Besides, studies on the C9orf72-mutant mice provided insights into the microbiota's role in mediating neuroinflammation, since broad-spectrum antibiotics treatment as well as transplanting gut microflora attenuated inflammation and autoimmunity implicated in neural degeneration (50). Recently, Blacher and colleagues confirmed a pre-symptomatic distinct microbiome composition in transgenic SODl mice and identified commensals such as, Parabacteroides distasonis and Ruminococcus torques adversely affected the disease whereas Akkermansia muciniphila ameliorated the disease (51). Using a combination of untargeted metabolomic profiling and metagenomics, they found 
that A. muciniphila increased nicotinamide (NAM) levels in the mice's cerebrospinal fluid, and NAM supplementation was able to improve the mice survival (43). Furthermore, the authors confirmed a distinct microbiome and metabolite configuration in a small group of ALS patients compared to healthy controls (51).

\section{POSSIBLE MECHANISMS UNDERLYING THE EFFECT OF GUT MICROBIOME ON THE PATHOGENESIS OF ALS}

Microbiota may influence the CNS and neuronal health either directly via the production of neuroactive metabolites (6) and toxins (7) or indirectly through modulation of immune response (52), dietary compounds, or drugs metabolism $(53,54)$ (Figure 1). For instance, gut microbes and their metabolites (e.g., SCFAs) can directly stimulate enterochromaffin cells to produce several neuropeptides (e.g., peptide YY, neuropeptide Y, cholecystokinin) or neurotransmitters (e.g., serotonin), which can diffuse into the bloodstream, reach the brain, and influence CNS functions. The intestinal epithelium regulates the translocation of specific bacterial products (e.g., SCFAs, vitamins, or neurotransmitters) into the bloodstream, which, in turn, through the circulatory system, can spread to the CNS (55). In this way, circulating microbiota-derived metabolites, neuropeptides and neurotransmitters can enter the CNS and directly influence its neurobiology.

Blecher et al. recently provided strong evidence for the microbial modulation of metabolites in ALS (51). Noting that the administration of A. muciniphila could improve the disease's course in mice, the authors applied an untargeted serum metabolomic profiling to identify a possible mediator. Interestingly, A. muciniphila treated mice displayed increased serum levels of NAM, whose direct administration showed beneficial effects, probably through modulation of mitochondrial function and oxidative stress pathways. NAM is a precursor of coenzymes required in energy transduction, signaling pathways, and antioxidant mechanisms that may be impaired in ALS-related neurodegeneration (56). Notably, the authors confirmed their findings in ALS patients, showing lower NAM concentration in their serum and CSF, and reduced expression of NAM synthesis bacterial genes in their stool when compared with healthy subjects (51), supporting the idea that GM can produce compounds capable of permeating the blood-brain barrier and influence neuronal function (57).

Another possible role of GM in ALS pathogenesis is the transformation of dietary and environmental compounds into neurotoxins. Beta-methylamino-lalanine (BMAA), a well-known neurotoxic amino acid found in the brains of ALS/ PDC patients from Guam (58), is thought to be produced in the gut from standard dietary compounds. For example, Cyanobacteria and other bacteria with anaerobic methylation functions can biosynthesize BMAA by methylation of L-serine and L-alanine. Enteric microbes can also convert amino acids such as L-tryptophan into bioactive molecules, such as indole, that once sulfonated can induce neuroinflammation and neuronal damage (59). GM can metabolize choline and L-carnitine into trimethylamine (TMA), and subsequently demethylate them into in dimethylamine (DMA) and formaldehyde (60). According to in vitro and in vivo studies, formaldehyde induces mitochondrial membrane damage, the 

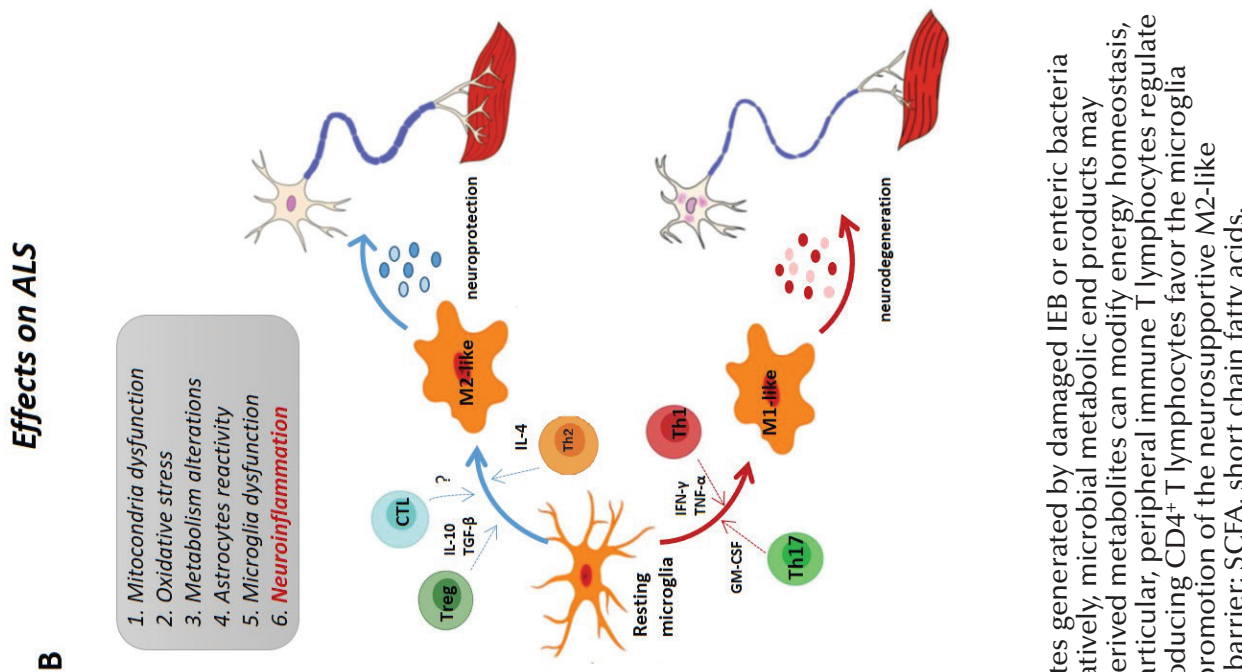

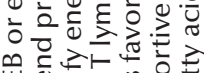

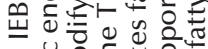
긍. 은 군윽. 

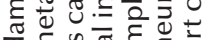
ठㄹㅇㅝ

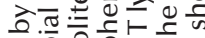

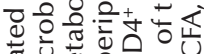
는 凹 $\varepsilon$ 迹

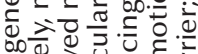
की

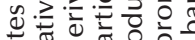
는

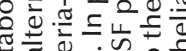
的额

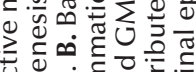
ชั 은 Q 记응

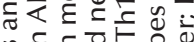

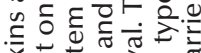

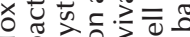

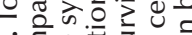

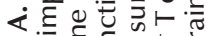
ง

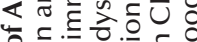

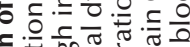
. 근 원

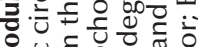

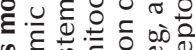
Q 考的的过

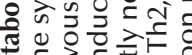

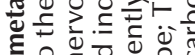

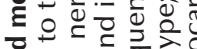

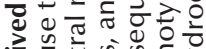

$\varangle \quad$ Intestinal permeability

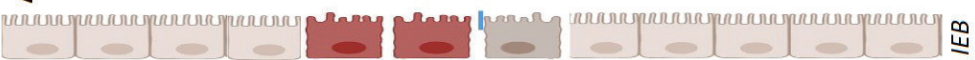

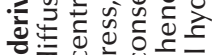

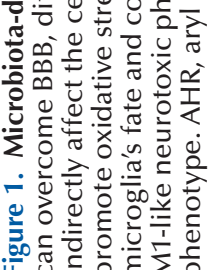


production of dangerous free radicals, and neuronal Tau protein misfolding and accumulation, thus contributing to ALS pathogenesis (61). Besides, the microbiota can bring on the negative effect of environmental pollutants. Exposure to polycyclic aromatic hydrocarbons (PAHs) is considered a risk factor for ALS $(62,63)$, and gut microbes can reverse the endogenous detoxification process of PAHs regenerating them as Benzo[a]pyrene (BaP), whose neurotoxic effect has been demonstrated in zebrafish (64). Further, gut dysbiosis may be the cause of metabolic alterations observed in ALS (65). Interestingly, gut dysbiosis and, in particular, the reduction in Firmicutes has been associated with greater REE (66), a possible explanation for the increased energy use displayed by ALS patients.

\section{EFFECTS OF MICROBIOTA-INDUCED INFLAMMATION ON THE PATHOGENESIS OF ALS}

An established key point of ALS pathogenesis is neuro-inflammation; it is related to a complex dysregulation of resident and peripheral immune cells (e.g., microglia and astrocytes activation, T cells infiltration, and increased pro-inflammatory mediators) (67). The GM communicates with the intestinal immune system, contributing to maintenance of immune tolerance and shaping immune responses during inflammation (68). Upon pathogen invasion or dysbiotic leaky gut, microbe-associated molecular patterns can stimulate innate cells to produce proinflammatory cytokines that, in turn, activate adaptive immune cells, thus contributing to the breakdown of immune homeostasis (69). Besides innate immune cells, intestinal microbes can directly affect the development and differentiation of the adaptive immune system's main components, the $\mathrm{CD} 4^{+}$and $\mathrm{CD} 8^{+} \mathrm{T}$ cells (70). In addition, GM dysbiosis affects several brain biological processes. Germ-free mice and antibiotic-treated mouse models display a broad range of immunological abnormalities, including altering density, morphology, and maturity of microglia, suggesting that GM can influence both CNS immune cells' development and functions (71).

Interestingly, treatment with SCFAs restored the microglia density and morphology in "depletion of regulatory T cells (DEREG)" mice. SCFAs such as butyric, propionic, and acetic acids are dietary fiber's end-metabolism microbial products, mainly by Bacteroides and Firmicutes (72). They are known to mediate regulatory T cell (Tregs) induction through histone deacetylase inhibition. ALS is characterized by simultaneous activation of distinct lymphocyte subsets, Th1 and Th17, and a decrease of Tregs (73) that have a protective role as demonstrated in both mice and humans; a greater number of Tregs is associated with slow disease progression $(74,75)$. Tregs have been shown to directly differentiate macrophages from M1 to M2 state (76), and M2 microglia has been associated with the stable disease phase, whereas Thl and Ml microglia predominate during the rapidly progressing phase suggesting a shift from protection to toxicity (Figure 1). Zhang et al. confirmed it, where butyrate supplementation appeared to reduce the clinical features of ALS and the immunology abnormalities found in the G93A mice's gut (49). Moreover, the longitudinal study by Figueroa-Romero et al. confirmed dysbiosis and spinal cord inflammation in SOD1 ${ }^{\mathrm{G} 93 \mathrm{~A}}$ mice, defining the 
chronological timeline, in which GM alterations precede circulating and CNS immune system expansion and activation, and symptom onset and progression (48). The study of Burberry et al. on C9orf72 null mice suggested that a dysbiosis characterized by immune-stimulating bacteria reduces mice survival by inducing detrimental peripheral inflammation and microglia activation, whereas antibiotic or the microbiota transplantation improved symptoms (50). Intestinal microbiota-driven proinflammatory signals may be essential for glia's physiological functioning, preserving neuronal health. Indeed, the gut microbiome regulates astrocyte activity through an aryl hydrocarbon receptor (AHR)-mediated mechanism involving type I interferon signaling (77).

\section{CLINICAL EVIDENCE THAT GUT MICROBIOME MODULATION IMPACTS ALS}

Studies in patients have begun to find a possible link between GM and ALS (Table 1), reporting controversial conclusions (78-87). The first studies conducted were characterized by small and select patient cohorts, with less than ten individuals, although they provided relatively consistent data in favor of dysbiosis in ALS (78-80). In these studies, the cause of pro-inflammatory dysbiosis is associated with the microbial imbalance that could compromise the intestinal epithelial barrier and promote immune/inflammatory responses with consequent alterations and a role in ALS pathogenesis.

Mazzini et al., in 2020, published a prospective longitudinal study on the microbiota composition in ALS $(81,82)$, demonstrating that the GM of ALS patients are different compared to controls, independent of the degree of disability. Moreover, they observed an increase of Cyanobacteria, noted for a neurotoxic action. Members of the Cyanobacteria phylum were significantly higher in the patients than in the controls, supporting the hypothesis that Cyanobacteria play a fundamental role in the pathogenesis of neurodegenerative diseases such as the ALS (84). Besides, Rowin et al. (79) and Nicholson et al. (85) observed that the glutamate metabolizer bacteria and the dominant butyrate-producing bacteria were, respectively, more abundant, and lower in ALS patients. In contrast, other studies showed that the fecal microbiome of patients with motoneuron disease was not significantly different from healthy controls $(86,87)$. However, a higher Firmicutes/Bacteroidetes ratio was associated with an increased risk of death and greater species diversity (87). These data support that the microbiota's alterations could modulate the disease's clinical course rather than representing a risk factor for its onset.

\section{CLINICAL CORRELATIONS AND POTENTIAL THERAPEUTIC APPROACHES}

In the first longitudinal study assessing GM in ALS (82), disease progression coincided with reduced microbial diversity, probably secondary to dietary changes, 


\section{TABLE 1 Studies investigating ALS microbiota}

\begin{tabular}{|c|c|c|}
\hline $\begin{array}{l}\text { Authors, year, } \\
\text { reference }\end{array}$ & $\begin{array}{l}\text { Participants \& } \\
\text { Methods }\end{array}$ & Results \\
\hline \multicolumn{3}{|c|}{ Studies in favor of gut microbiota dysbiosis in ALS } \\
\hline $\begin{array}{l}\text { Fang et al., } \\
2016(78)\end{array}$ & $\begin{array}{l}\text { - case-control } \\
\text { (6 P and } 5 \mathrm{C})\end{array}$ & $\begin{array}{l}\text { - decreased Firmicutes/Bacteroidetes ratio at phylum level in P } \\
\text { - significant increased genus Dorea (harmful microorganisms) } \\
\text { and significant reduced genus Oscillibacter, Anaerostipes, } \\
\text { Lachnospiraceae (beneficial microorganisms) in P }\end{array}$ \\
\hline $\begin{array}{l}\text { Rowin et al., } \\
2017 \text { (79) }\end{array}$ & $\begin{array}{l}\text { - case-control } \\
\quad(5 \mathrm{P} \text { and } 96 \mathrm{C})\end{array}$ & $\begin{array}{l}\text { - the genera Lactobacillus, Bifidobacterium, and Odoribacter } \\
\text { (glutamate metabolizers) are more abundant in P }\end{array}$ \\
\hline $\begin{array}{l}\text { Zhai et al., } \\
\qquad 2019(80)\end{array}$ & $\begin{array}{l}\text { - } \quad \text { case-control } \\
\text { (8 P and } 8 \mathrm{C})\end{array}$ & $\begin{array}{l}\text { - the phylum Firmicutes/Bacteroidetes ratio, genus } \\
\text { Methanobrevibacter, showed an enhancive tendency in P } \\
\text { - the relative abundance of beneficial micro-organisms } \\
\text { (genera Faecalibacterium and Bacteroides) presented a } \\
\text { significant decrease tendency in P }\end{array}$ \\
\hline $\begin{array}{l}\text { Mazzini et al., } \\
2018(81)\end{array}$ & $\begin{array}{l}\text { - prospective } \\
\text { longitudinal }\end{array}$ & $\begin{array}{l}\text { - GM of } \mathrm{P} \text { is characterized by some differences compared } \\
\text { to } \mathrm{C} \text {, regardless of the disability degree }\end{array}$ \\
\hline $\begin{array}{l}\text { Di Gioia et al., } \\
2020 \text { (82) }\end{array}$ & $\begin{array}{l}\text { study } \\
\text { - } \text { case-control } \\
\text { ( } 50 \mathrm{P} \text { and } 50 \mathrm{C}) \\
\text { - } \text { probiotic } \\
\text { supplementation }\end{array}$ & $\begin{array}{l}\text { the GM composition changed over the disease course } \\
\text { (significant decrease in the number of the observed } \\
\text { operational taxonomic units during the follow-up) } \\
\text { - probiotic supplementation has no effect on disease } \\
\text { progression }\end{array}$ \\
\hline Zeng, 2020 (83) & $\begin{array}{l}\text { - } \text { case-control } \\
\text { (20 P and } 20 \mathrm{C})\end{array}$ & $\begin{array}{l}\text { - over-representation of Bacteroidetes phylum and other } \\
\text { bacterial genera in P } \\
\text { - Firmicutes and Megamonas genus down-regulated in P, } \\
\text { with reduced Firmicutes/Bacteroidetes ratio } \\
\text { - increased species diversity associated with P compared to C }\end{array}$ \\
\hline $\begin{array}{l}\text { Nicholson } \\
\text { et al., } 2020 \\
\text { (85) }\end{array}$ & $\begin{array}{l}\text { - case-control } \\
\text { (66 P, 61 C and } \\
12 \mathrm{NC})\end{array}$ & $\begin{array}{l}\text { - relative abundance of the dominant butyrate-producing } \\
\text { bacteria Eubacterium rectale and Roseburia intestinalis was } \\
\text { lower in P compared to C } \\
\text { - total abundance of } 8 \text { dominant species capable of } \\
\text { producing butyrate was lower in P, independently from age, } \\
\text { sex or presence of constipation }\end{array}$ \\
\hline
\end{tabular}

Studies not in favor of gut microbiota dysbiosis in ALS

\begin{tabular}{|c|c|c|}
\hline $\begin{array}{c}\text { Brenner et al., } \\
2018 \text { (86) }\end{array}$ & $\begin{array}{l}\text { - } \quad \text { case-control } \\
\text { (25 P and } 32 \mathrm{C})\end{array}$ & $\begin{array}{l}\text { - no substantial alteration of the GM composition } \\
\text { significant differences only in the overall number of } \\
\text { microbial species and the abundance of uncultured } \\
\text { Ruminococcaceae in P }\end{array}$ \\
\hline $\begin{array}{l}\text { Ngo et al., } 2020 \\
\quad(87)\end{array}$ & $\begin{array}{l}\text { - } \text { case-control } \\
\text { (49 P and } 50 \mathrm{C} \text { ) }\end{array}$ & $\begin{array}{l}\text { - no correlation between metabolic and clinical features of } \mathrm{P} \\
\text { and the composition of their fecal microbiome } \\
\text { - greater risk for earlier death in } \mathrm{P} \text { with increased richness } \\
\text { and diversity of the microbiome and in those with greater } \\
\text { Firmicutes to Bacteroidetes ratio }\end{array}$ \\
\hline
\end{tabular}

Overall, ALS seems to be characterized by the reduction of butyrate-producing bacteria, which are important for gut integrity and regulation of inflammation. However, some discrepancies are present. ALS, amyotrophic lateral sclerosis; C, controls; GM, gut microbiota; NC, neurodegenerative controls; P, ALS patients. 
highlighting that the interpretation of the results cannot be separated from diet monitoring and other factors that influence the microbiota (e.g., drug use, like antibiotics), and the stage of the disease. Furthermore, antibiotics alter the balance of intestinal microbial species (88); this opens a window on correlations between antibiotic use and unrelated diseases. Retrospective epidemiological studies in Swedish national registries showed that antibiotics, especially if repeated, were associated with an increased risk of developing ALS (89). These results, generated independently of the type of infection and the antibiotics, suggest that this relation was not specific to a particular organ system. After testing several antibiotics classes, only beta-lactamase-sensitive penicillin use was significantly associated with increased odds of developing ALS. The authors concluded that the most probable pathogenic mechanism was antibiotic-induced perturbations of the intestinal microflora (89).

Although evidence on the GM's role in ALS is increasing, the available studies are primarily exploratory; the number of cohorts remains small, which, in consideration of the significant inter-individual variability and clinical heterogeneity that characterizes ALS, could preclude the identification of the relevant characteristics of the microbiome. These results show the importance of large cohorts and multicenter studies, allowing to consider intra-group differences in the ALS population (genetically or phenotypically determined and concerning disease stage) as well as changes between groups between ALS and controls. Microbiota's specific signature may be protective or toxic in different individuals and for diverse genetic backgrounds.

Regarding the implications for ALS patients' treatment, a longitudinal analysis of the microbiota composition after supplementation with placebo or probiotic treatment revealed a significant decrease in the observed operational taxonomic units number during the follow-up, with the predominance of neurotoxic or pro-inflammatory microbial groups such as Cyanobacteria (82). Supplementation with probiotics, though having some effects on the intestinal microflora of ALS patients, did not substantially bring the composition closer to that of healthy subjects (82), implying more drastic interventions are required to reach such a target, as this type of treatment remains a minimal intervention in time and quantitative terms, concerning the abundance of species hosted by the intestine. In this regard, we are coordinating a multicenter controlled clinical trial in Italy that involves transplantation of fecal microbiota in 42 patients with ALS. Fecal microbiota transplantation is planned at baseline and after six months; an extensive immunological profile and microbiota characterization are ongoing (90).

Another relatively unexplored issue regards the fact that microbiota may also influence specific drug availability in ALS. Riluzole is significantly metabolized by GM $(54,90)$, which may explain interpatient variability in the drug plasma levels (92). It may be argued that similar effects would also be found for experimental drugs tested in ALS patients, which may contribute to hurdles in finding a cure for ALS. Finally, GM may influence non-motor symptoms in ALS such as depression, anxiety, and constipation through peptides and neurotransmitters that could directly impact mood (93), opening the possibility for treatment to improve at least the quality of life of ALS patients. 


\section{CONCLUSION}

This chapter highlights the possible role of gut microbiome in the pathogenesis of ALS. Many studies on animal models of ALS have revealed changes in the intestinal flora; however, most of the experimental evidence in humans has come from correlation research; many studies mainly describe the alterations of intestinal flora in ALS patients. Emerging evidence shows that GM can influence ALS through hypermetabolism and gastrointestinal abnormalities. Other interesting associations have been reported based on which microbiota could play a role in the interface between environmental and lifestyle factors, and ALS. By studying these associations, we may gain more insight into the complex network of microbiomehost interactions underlying the observed changes in ALS. Longitudinal studies integrating metagenomic, transcriptomic, and metabolomic approaches with clinical parameters may elucidate the relationships between established risk modifiers, gut microbiota, and ALS. Although we still need to establish a "cause and effect" relationship between GM and ALS, the strategy of regulating intestinal microbial flora to treat this devastating disease is intriguing. Further rigorous studies targeting GM may develop novel approaches for the prevention and treatment of ALS.

Acknowledgement: This study was partly funded by the AGING Project for Department of Excellence at the Department of Translational Medicine (DIMET), Università del Piemonte Orientale, Novara, Italy.

Conflict of Interest: The authors declare no potential conflict of interest with respect to research, authorship and/or publication of this chapter.

Copyright and Permission Statement: The authors confirm that the materials included in this chapter do not violate copyright laws. Where relevant, appropriate permissions have been obtained from the original copyright holder(s), and all original sources have been appropriately acknowledged or referenced.

\section{REFERENCES}

1. Tesauro M, Bruschi M, Filippini T, D’Alfonso S, Mazzini L, Corrado L, et al. Metal(loid)s role in the pathogenesis of amyotrophic lateral sclerosis: Environmental, epidemiological, and genetic data. Environ Res. 2021;192:110292. https://doi.org/10.1016/j.envres.2020.110292

2. Pupillo E, Bianchi E, Chiò A, Casale F, Zecca C, Tortelli R, et al. Amyotrophic lateral sclerosis and food intake. Amyotroph Lateral Scler Frontotemporal Degener. 2018;19(3-4):267-74. https://doi.org/10. 1080/21678421.2017.1418002

3. Nelson LM, Matkin C, Longstreth WTJ, McGuire V. Population-based case-control study of amyotrophic lateral sclerosis in western Washington State. II. Diet. Am J Epidemiol. 2000;151(2):164-73. https://doi.org/10.1093/oxfordjournals.aje.a010184

4. Dieterich W, Schink M, Zopf Y. Microbiota in the Gastrointestinal Tract. Med Sci (Basel, Switzerland). 2018;6(4). https://doi.org/10.3390/medsci6040116

5. Wang H-X, Wang Y-P. Gut Microbiota-brain Axis. Chin Med J (Engl). 2016;129(19):2373-80. https:// doi.org/10.4103/0366-6999.190667 
6. De Vadder F, Kovatcheva-Datchary P, Goncalves D, Vinera J, Zitoun C, Duchampt A, et al. Microbiota-generated metabolites promote metabolic benefits via gut-brain neural circuits. Cell. 2014;156(1-2):84-96. https://doi.org/10.1016/j.cell.2013.12.016

7. Brenner SR. Blue-green algae or cyanobacteria in the intestinal micro-flora may produce neurotoxins such as Beta-N-Methylamino-L-Alanine (BMAA) which may be related to development of amyotrophic lateral sclerosis, Alzheimer's disease and Parkinson-Dementia-Complex i. Vol. 80, Medical hypotheses. United States; 2013. p. 103. https://doi.org/10.1016/j.mehy.2012.10.010

8. Tysnes O-B. Treatment of sialorrhea in amyotrophic lateral sclerosis. Acta Neurol Scand Suppl. 2008;188:77-81. https://doi.org/10.1111/j.1600-0404.2008.01037.x

9. Garuti G, Rao F, Ribuffo V, Sansone VA. Sialorrhea in patients with ALS: current treatment options. Degener Neurol Neuromuscul Dis. 2019;9:19-26. https://doi.org/10.2147/DNND.S168353

10. Blackhall LJ. Amyotrophic lateral sclerosis and palliative care: where we are, and the road ahead. Muscle Nerve. 2012;45(3):311-8. https://doi.org/10.1002/mus.22305

11. Kurian KM, Forbes RB, Colville S, Swingler RJ. Cause of death and clinical grading criteria in a cohort of amyotrophic lateral sclerosis cases undergoing autopsy from the Scottish Motor Neurone Disease Register. J Neurol Neurosurg Psychiatry. 2009;80(1):84-7. https://doi.org/10.1136/jnnp.2008.149708

12. Weikamp JG, Schinagl DAX, Verstappen CCP, Schelhaas HJ, de Swart BJM, Kalf JG. Botulinum toxinA injections vs radiotherapy for drooling in ALS. Acta Neurol Scand. 2016;134(3):224-31. https:// doi.org/10.1111/ane.12559

13. Nübling GS, Mie E, Bauer RM, Hensler M, Lorenzl S, Hapfelmeier A, et al. Increased prevalence of bladder and intestinal dysfunction in amyotrophic lateral sclerosis. Amyotroph Lateral Scler Frontotemporal Degener. 2014;15(3-4):174-9. https://doi.org/10.3109/21678421.2013.868001

14. Toepfer M, Schroeder M, Klauser A, Lochmüller H, Hirschmann M, Riepl RL, et al. Delayed colonic transit times in amyotrophic lateral sclerosis assessed with radio-opaque markers. Eur J Med Res. 1997;2(11):473-6.

15. Toepfer M, Folwaczny C, Klauser A, Riepl RL, Müller-Felber W, Pongratz D. Gastrointestinal dysfunction in amyotrophic lateral sclerosis. Amyotroph lateral Scler other Mot neuron Disord Off Publ World Fed Neurol Res Gr Mot Neuron Dis. 1999;1(1):15-9. https://doi.org/10.1080/146608299300079484

16. Piccione EA, Sletten DM, Staff NP, Low PA. Autonomic system and amyotrophic lateral sclerosis. Muscle Nerve. 2015;51(5):676-9. https://doi.org/10.1002/mus.24457

17. Abrahamsson H, Ostlund-Lindqvist A-M, Nilsson R, Simrén M, Gillberg P-G. Altered bile acid metabolism in patients with constipation-predominant irritable bowel syndrome and functional constipation. Scand J Gastroenterol. 2008;43(12):1483-8. https://doi.org/10.1080/00365520802321212

18. Zhuang M, Shang W, Ma Q, Strappe P, Zhou Z. Abundance of Probiotics and Butyrate-Production Microbiome Manages Constipation via Short-Chain Fatty Acids Production and Hormones Secretion. Mol Nutr Food Res. 2019;63(23):e1801187. https://doi.org/10.1002/mnfr.201801187

19. Pimentel M, Lin HC, Enayati P, van den Burg B, Lee H-R, Chen JH, et al. Methane, a gas produced by enteric bacteria, slows intestinal transit and augments small intestinal contractile activity. Am J Physiol Gastrointest Liver Physiol. 2006;290(6):G1089-95. https://doi.org/10.1152/ajpgi.00574.2004

20. Parthasarathy G, Chen J, Chen X, Chia N, O'Connor HM, Wolf PG, et al. Relationship Between Microbiota of the Colonic Mucosa vs Feces and Symptoms, Colonic Transit, and Methane Production in Female Patients With Chronic Constipation. Gastroenterology. 2016;150(2):367-79.e1. https:// doi.org/10.1053/j.gastro.2015.10.005

21. Furness JB. The enteric nervous system and neurogastroenterology. Nat Rev Gastroenterol Hepatol. 2012;9(5):286-94. https://doi.org/10.1038/nrgastro.2012.32

22. Quigley EMM. Microbiota-Brain-Gut Axis and Neurodegenerative Diseases. Curr Neurol Neurosci Rep. 2017;17(12):94. https://doi.org/10.1007/s11910-017-0802-6

23. Onesti E, Schettino I, Gori MC, Frasca V, Ceccanti M, Cambieri C, et al. Dysphagia in Amyotrophic Lateral Sclerosis: Impact on Patient Behavior, Diet Adaptation, and Riluzole Management. Front Neurol. 2017;8:94. https://doi.org/10.3389/fneur.2017.00094

24. Andersen PM, Abrahams S, Borasio GD, de Carvalho M, Chio A, Van Damme P, et al. EFNS guidelines on the clinical management of amyotrophic lateral sclerosis (MALS)--revised report of an EFNS task force. Eur J Neurol. 2012;19(3):360-75. https://doi.org/10.1111/j.1468-1331.2011.03501.x 
25. Stavroulakis T, Walsh T, Shaw PJ, McDermott CJ. Gastrostomy use in motor neurone disease (MND): a review, meta-analysis and survey of current practice. Amyotroph Lateral Scler Frontotemporal Degener. 2013;14(2):96-104. https://doi.org/10.3109/17482968.2012.723722

26. Jie Z, Yu X, Liu Y, Sun L, Chen P, Ding Q, et al. The baseline gut microbiota directs dieting-induced weight loss trajectories. Gastroenterology. 2021; https://doi.org/10.1053/j.gastro.2021.01.029

27. de Vries T, de Ruiter A, Westendorp A, van Zeijl J. Microorganisms and complaints in outpatients with a percutaneous endoscopic gastrostomy catheter. Am J Infect Control. 2015;43(8):802-4. https://doi. org/10.1016/j.ajic.2015.04.002

28. Hobson E V, McDermott CJ. Supportive and symptomatic management of amyotrophic lateral sclerosis. Nat Rev Neurol. 2016;12(9):526. https://doi.org/10.1038/nrneurol.2016.111

29. Desport JC, Preux PM, Truong TC, Vallat JM, Sautereau D, Couratier P. Nutritional status is a prognostic factor for survival in ALS patients. Neurology. 1999;53(5):1059-63. https://doi.org/10.1212/ WNL.53.5.1059

30. Bouteloup C, Desport J-C, Clavelou P, Guy N, Derumeaux-Burel H, Ferrier A, et al. Hypermetabolism in ALS patients: an early and persistent phenomenon. J Neurol. 2009;256(8):1236-42. https://doi. org/10.1007/s00415-009-5100-z

31. Funalot B, Desport J-C, Sturtz F, Camu W, Couratier P. High metabolic level in patients with familial amyotrophic lateral sclerosis. Amyotroph lateral Scler Off Publ World Fed Neurol Res Gr Mot Neuron Dis. 2009;10(2):113-7. https://doi.org/10.1080/17482960802295192

32. Loeffler J-P, Picchiarelli G, Dupuis L, Gonzalez De Aguilar J-L. The Role of Skeletal Muscle in Amyotrophic Lateral Sclerosis. Brain Pathol. 2016;26(2):227-36. https://doi.org/10.1111/ bpa. 12350

33. Steyn FJ, Ioannides ZA, van Eijk RPA, Heggie S, Thorpe KA, Ceslis A, et al. Hypermetabolism in ALS is associated with greater functional decline and shorter survival. J Neurol Neurosurg Psychiatry. 2018;89(10):1016-23. https://doi.org/10.1136/jnnp-2017-317887

34. Georges M, Morélot-Panzini C, Similowski T, Gonzalez-Bermejo J. Noninvasive ventilation reduces energy expenditure in amyotrophic lateral sclerosis. BMC Pulm Med. 2014;14:17. https://doi. org/10.1186/1471-2466-14-17

35. Reich-Slotky R, Andrews J, Cheng B, Buchsbaum R, Levy D, Kaufmann P, et al. Body mass index (BMI) as predictor of ALSFRS-R score decline in ALS patients. Amyotroph Lateral Scler Frontotemporal Degener. 2013;14(3):212-6. https://doi.org/10.3109/21678421.2013.770028

36. Gallo V, Wark PA, Jenab M, Pearce N, Brayne C, Vermeulen R, et al. Prediagnostic body fat and risk of death from amyotrophic lateral sclerosis: the EPIC cohort. Neurology. 2013;80(9):829-38. https:// doi.org/10.1212/WNL.0b013e3182840689

37. Paganoni S, Deng J, Jaffa M, Cudkowicz ME, Wills A-M. Body mass index, not dyslipidemia, is an independent predictor of survival in amyotrophic lateral sclerosis. Muscle Nerve. 2011;44(1):20-4. https://doi.org/10.1002/mus.22114

38. Echaniz-Laguna A, Zoll J, Ribera F, Tranchant C, Warter J-M, Lonsdorfer J, et al. Mitochondrial respiratory chain function in skeletal muscle of ALS patients. Ann Neurol. 2002;52(5):623-7. https://doi. org/10.1002/ana.10357

39. Dupuis L, Corcia P, Fergani A, Gonzalez De Aguilar J-L, Bonnefont-Rousselot D, Bittar R, et al. Dyslipidemia is a protective factor in amyotrophic lateral sclerosis. Neurology. 2008;70(13):1004-9. https://doi.org/10.1212/01.wnl.0000285080.70324.27

40. Zinman L, Sadeghi R, Gawel M, Patton D, Kiss A. Are statin medications safe in patients with ALS? Amyotroph lateral Scler Off Publ World Fed Neurol Res Gr Mot Neuron Dis. 2008;9(4):223-8. https://doi.org/10.1080/17482960802031092

41. Ahmed RM, Irish M, Piguet O, Halliday GM, Ittner LM, Farooqi S, et al. Amyotrophic lateral sclerosis and frontotemporal dementia: distinct and overlapping changes in eating behaviour and metabolism. Lancet Neurol. 2016;15(3):332-42. https://doi.org/10.1016/S1474-4422 (15)00380-4

42. Gorges M, Vercruysse P, Müller H-P, Huppertz H-J, Rosenbohm A, Nagel G, et al. Hypothalamic atrophy is related to body mass index and age at onset in amyotrophic lateral sclerosis. J Neurol Neurosurg Psychiatry. 2017;88(12):1033-41. https://doi.org/10.1136/jnnp-2017-315795 
43. Gotkine M, Kviatcovsky D, Elinav E. Amyotrophic lateral sclerosis and intestinal microbiota-toward establishing cause and effect. Gut Microbes. 2020;11(6):1833-41. https://doi.org/10.1080/19490976 .2020 .1767464

44. Kouchaki E, Tamtaji OR, Salami M, Bahmani F, Daneshvar Kakhaki R, Akbari E, et al. Clinical and metabolic response to probiotic supplementation in patients with multiple sclerosis: A randomized, double-blind, placebo-controlled trial. Clin Nutr. 2017;36(5):1245-9. https://doi.org/10.1016/j. clnu.2016.08.015

45. Akbari E, Asemi Z, Daneshvar Kakhaki R, Bahmani F, Kouchaki E, Tamtaji OR, et al. Effect of Probiotic Supplementation on Cognitive Function and Metabolic Status in Alzheimer's Disease: A Randomized, Double-Blind and Controlled Trial. Front Aging Neurosci. 2016;8:256. https://doi.org/10.3389/ fnagi.2016.00256

46. Tamtaji OR, Taghizadeh M, Daneshvar Kakhaki R, Kouchaki E, Bahmani F, Borzabadi S, et al. Clinical and metabolic response to probiotic administration in people with Parkinson's disease: A randomized, double-blind, placebo-controlled trial. Clin Nutr. 2019;38(3):1031-5. https://doi.org/10.1016/j. clnu.2018.05.018

47. Wu S, Yi J, Zhang Y, Zhou J, Sun J. Leaky intestine and impaired microbiome in an amyotrophic lateral sclerosis mouse model. Physiol Rep. 2015;3(4). https://doi.org/10.14814/phy2.12356

48. Figueroa-Romero C, Guo K, Murdock BJ, Paez-Colasante X, Bassis CM, Mikhail KA, et al. Temporal evolution of the microbiome, immune system and epigenome with disease progression in ALS mice. Dis Model Mech. 2019;13(2). https://doi.org/10.1242/dmm.041947

49. Zhang Y, Wu S, Yi J, Xia Y, Jin D, Zhou J, et al. Target intestinal microbiota to alleviate disease progression in amyotrophic lateral sclerosis. Clin Ther. 2017;39(2):322-36. https://doi.org/10.1016/j. clinthera.2016.12.014

50. Burberry A, Wells MF, Limone F, Couto A, Smith KS, Keaney J, et al. C9orf72 suppresses systemic and neural inflammation induced by gut bacteria. Nature. 2020;1-6. https://doi.org/10.1038/ s41586-020-2288-7

51. Blacher E, Bashiardes S, Shapiro H, Rothschild D, Mor U, Dori-Bachash M, et al. Potential roles of gut microbiome and metabolites in modulating ALS in mice. Nature. 2019;572(7770):474-80. https:// doi.org/10.1038/s41586-019-1443-5

52. Ma Q, Xing C, Long W, Wang HY, Liu Q, Wang R-F. Impact of microbiota on central nervous system and neurological diseases: the gut-brain axis. J Neuroinflammation. 2019;16(1):53. https://doi. org/10.1186/s12974-019-1434-3

53. Longstreth WTJ, Meschke JS, Davidson SK, Smoot LM, Smoot JC, Koepsell TD. Hypothesis: a motor neuron toxin produced by a clostridial species residing in gut causes ALS. Med Hypotheses. 2005;64(6):1153-6. https://doi.org/10.1016/j.mehy.2004.07.041

54. Zimmermann M, Zimmermann-Kogadeeva M, Wegmann R, Goodman AL. Mapping human microbiome drug metabolism by gut bacteria and their genes. Nature. 2019;570(7762):462-7. https://doi. org/10.1038/s41586-019-1291-3

55. Fung TC, Olson CA, Hsiao EY. Interactions between the microbiota, immune and nervous systems in health and disease. Nat Neurosci. 2017;20(2):145-55. https://doi.org/10.1038/nn.4476

56. Smith EF, Shaw PJ, De Vos KJ. The role of mitochondria in amyotrophic lateral sclerosis. Neurosci Lett. 2019;710:132933. https://doi.org/10.1016/j.neulet.2017.06.052

57. Blacher E, Levy M, Tatirovsky E, Elinav E. Microbiome-Modulated Metabolites at the Interface of Host Immunity. J Immunol. 2017;198(2):572-80. https://doi.org/10.4049/jimmunol.1601247

58. Murch SJ, Cox PA, Banack SA, Steele JC, Sacks OW. Occurrence of beta-methylamino-l-alanine (BMAA) in ALS/PDC patients from Guam. Acta Neurol Scand. 2004;110(4):267-9. https://doi. org/10.1111/j.1600-0404.2004.00320.x

59. Adesso S, Ruocco M, Rapa SF, Piaz FD, Raffaele Di Iorio B, Popolo A, et al. Effect of Indoxyl Sulfate on the Repair and Intactness of Intestinal Epithelial Cells: Role of Reactive Oxygen Species' Release. Int J Mol Sci. 2019;20(9). https://doi.org/10.3390/ijms20092280

60. Fennema D, Phillips IR, Shephard EA. Trimethylamine and Trimethylamine N-Oxide, a FlavinContaining Monooxygenase 3 (FMO3)-Mediated Host-Microbiome Metabolic Axis Implicated in Health and Disease. Drug Metab Dispos. 2016;44(11):1839-50. https://doi.org/10.1124/dmd. 116.070615 
61. Szende B, Tyihák E. Effect of formaldehyde on cell proliferation and death. Cell Biol Int. 2010;34(12):1273-82. https://doi.org/10.1042/CBI20100532

62. Dickerson AS, Hansen J, Gredal O, Weisskopf MG. Amyotrophic Lateral Sclerosis and Exposure to Diesel Exhaust in a Danish Cohort. Am J Epidemiol. 2018;187(8):1613-22. https://doi.org/10.1093/ aje/kwy069

63. Ash PEA, Stanford EA, Al Abdulatif A, Ramirez-Cardenas A, Ballance HI, Boudeau S, et al. Dioxins and related environmental contaminants increase TDP-43 levels. Mol Neurodegener. 2017;12(1):35. https://doi.org/10.1186/s13024-017-0177-9

64. Gao D, Wu M, Wang C, Wang Y, Zuo Z. Chronic exposure to low benzo[a]pyrene level causes neurodegenerative disease-like syndromes in zebrafish (Danio rerio). Aquat Toxicol. 2015;167:200-8. https://doi.org/10.1016/j. aquatox.2015.08.013

65. Ngo ST, Mi JD, Henderson RD, McCombe PA, Steyn FJ. Exploring targets and therapies for amyotrophic lateral sclerosis: current insights into dietary interventions. Degener Neurol Neuromuscul Dis. 2017;7:95-108. https://doi.org/10.2147/DNND.S120607

66. Kocełak P, Zak-Gołąb A, Zahorska-Markiewicz B, Aptekorz M, Zientara M, Martirosian G, et al. Resting energy expenditure and gut microbiota in obese and normal weight subjects. Eur Rev Med Pharmacol Sci. 2013;17(20):2816-21. https://doi.org/10.1155/2013/674106

67. Béland L-C, Markovinovic A, Jakovac H, de Marchi F, Bilic E, Mazzini L, et al. Immunity in amyotrophic lateral sclerosis: blurred lines between excessive inflammation and inefficient immune responses. Brain Commun. 2020; https://doi.org/10.1093/braincomms/fcaal24

68. Shi N, Li N, Duan X, Niu H. Interaction between the gut microbiome and mucosal immune system. Mil Med Res. 2017;4:14. https://doi.org/10.1186/s40779-017-0122-9

69. Maynard CL, Elson CO, Hatton RD, Weaver CT. Reciprocal interactions of the intestinal microbiota and immune system. Nature. 2012;489(7415):231-41. https://doi.org/10.1038/nature11551

70. Wu H-J, Wu E. The role of gut microbiota in immune homeostasis and autoimmunity. Gut Microbes. 2012;3(1):4-14. https://doi.org/10.4161/gmic. 19320

71. Erny D, Hrabě de Angelis AL, Jaitin D, Wieghofer P, Staszewski O, David E, et al. Host microbiota constantly control maturation and function of microglia in the CNS. Nat Neurosci. 2015;18(7):965-77. https://doi.org/10.1038/nn.4030

72. Kehrmann J, Effenberg L, Wilk C, Schoemer D, Ngo Thi Phuong N, Adamczyk A, et al. Depletion of Foxp3(+) regulatory $\mathrm{T}$ cells is accompanied by an increase in the relative abundance of Firmicutes in the murine gut microbiome. Immunology. 2020;159(3):344-53. https://doi.org/10.1111/imm.13158

73. Saresella M, Piancone F, Tortorella P, Marventano I, Gatti A, Caputo D, et al. T helper-17 activation dominates the immunologic milieu of both amyotrophic lateral sclerosis and progressive multiple sclerosis. Clin Immunol. 2013;148(1):79-88. https://doi.org/10.1016/j.clim.2013.04.010

74. Henkel JS, Beers DR, Wen S, Rivera AL, Toennis KM, Appel JE, et al. Regulatory T-lymphocytes mediate amyotrophic lateral sclerosis progression and survival. EMBO Mol Med. 2013;5(1):64-79. https:// doi.org/10.1002/emmm.201201544

75. Beers DR, Henkel JS, Zhao W, Wang J, Huang A, Wen S, et al. Endogenous regulatory T lymphocytes ameliorate amyotrophic lateral sclerosis in mice and correlate with disease progression in patients with amyotrophic lateral sclerosis. Brain. 2011;134(Pt 5):1293-314. https://doi.org/10.1093/brain/ awr074

76. Tiemessen MM, Jagger AL, Evans HG, van Herwijnen MJC, John S, Taams LS. CD4+CD25+Foxp3+ regulatory T cells induce alternative activation of human monocytes/macrophages. Proc Natl Acad Sci U S A. 2007;104(49):19446-51. https://doi.org/10.1073/pnas.0706832104

77. Rothhammer V, Mascanfroni ID, Bunse L, Takenaka MC, Kenison JE, Mayo L, et al. Type I interferons and microbial metabolites of tryptophan modulate astrocyte activity and central nervous system inflammation via the aryl hydrocarbon receptor. Nat Med. 2016;22(6):586-97. https://doi. org $/ 10.1038 / \mathrm{nm} .4106$

78. Fang X, Wang X, Yang S, Meng F, Wang X, Wei H, et al. Evaluation of the microbial diversity in amyotrophic lateral sclerosis using high-throughput sequencing. Front Microbiol. 2016;7:1479. https:// doi.org/10.3389/fmicb.2016.01479

79. Rowin J, Xia Y, Jung B, Sun J. Gut inflammation and dysbiosis in human motor neuron disease. Physiol Rep. 2017;5(18). https://doi.org/10.14814/phy2.13443 
80. Zhai C-D, Zheng J-J, An B-C, Huang H-F, Tan Z-C. Intestinal microbiota composition in patients with amyotrophic lateral sclerosis: establishment of bacterial and archaeal communities analyses. Chin Med J (Engl). 2019;132(15):1815. https://doi.org/10.1097/CM9.0000000000000351

81. Mazzini L, Mogna L, De Marchi F, Amoruso A, Pane M, Aloisio I, et al. Potential Role of Gut Microbiota in ALS Pathogenesis and Possible Novel Therapeutic Strategies. J Clin Gastroenterol. 2018;52. https:// doi.org/10.1097/MCG.0000000000001042

82. Di Gioia D, Cionci NB, Baffoni L, Amoruso A, Pane M, Mogna L, et al. A prospective longitudinal study on the microbiota composition in amyotrophic lateral sclerosis. BMC Med. 2020;18(1):1-19. https://doi.org/10.1186/s12916-020-01607-9

83. Zeng Q, Shen J, Chen K, Zhou J, Liao Q, Lu K, et al. The alteration of gut microbiome and metabolism in amyotrophic lateral sclerosis patients. Sci Rep. 2020;10(1):12998. doi: https://doi.org/10.1038/ s41598-020-69845-8

84. Cox PA, Banack SA, Murch SJ. Biomagnification of cyanobacterial neurotoxins and neurodegenerative disease among the Chamorro people of Guam. Proc Natl Acad Sci. 2003;100(23):13380-3. https:// doi.org/10.1073/pnas.2235808100

85. Nicholson K, Bjornevik K, Abu-Ali G, Chan J, Cortese M, Dedi B, et al. The human gut microbiota in people with amyotrophic lateral sclerosis. Amyotroph Lateral Scler Front Degener. 2020;1-9.

86. Brenner D, Hiergeist A, Adis C, Mayer B, Gessner A, Ludolph AC, et al. The fecal microbiome of ALS patients. Neurobiol Aging. 2018;61:132-7. https://doi.org/10.1016/j.neurobiolaging.2017.09.023

87. Ngo ST, Restuadi R, McCrae AF, Van Eijk RP, Garton F, Henderson RD, et al. Progression and survival of patients with motor neuron disease relative to their fecal microbiota. Amyotroph Lateral Scler Frontotemporal Degener. 2020;21(7-8):549-62. https://doi.org/10.1080/21678421.2020.1772825

88. Willing BP, Russell SL, Finlay BB. Shifting the balance: antibiotic effects on host-microbiota mutualism. Nat Rev Microbiol. 2011;9(4):233-43. https://doi.org/10.1038/nrmicro2536

89. Sun J, Zhan Y, Mariosa D, Larsson H, Almqvist C, Ingre C, et al. Antibiotics Use and Risk of Amyotrophic Lateral Sclerosis in Sweden. Eur J Neurol. 2019; https://doi.org/10.1111/ene.13986

90. Mandrioli J, Amedei A, Cammarota G, Niccolai E, Zucchi E, Ricci F, et al. FETR-ALS study protocol: a randomized clinical trial of fecal microbiota transplantation in amyotrophic lateral sclerosis. Front Neurol. 2019;10:1021. https://doi.org/10.3389/fneur.2019.01021

91. Bensimon G, Lacomblez L, Meininger V. A controlled trial of riluzole in amyotrophic lateral sclerosis. ALS/Riluzole Study Group. N Engl J Med. 1994;330(9):585-91. https://doi.org/10.1056/ NEJM199403033300901

92. Zarate Jr CA, Manji HK. Riluzole in psychiatry: a systematic review of the literature. Expert Opin Drug Metab Toxicol. 2008;4(9):1223-34. https://doi.org/10.1517/17425255.4.9.1223

93. Lach G, Schellekens H, Dinan TG, Cryan JF. Anxiety, Depression, and the Microbiome: A Role for Gut Peptides. Neurother J Am Soc Exp Neurother. 2018;15(1):36-59. https://doi.org/10.1007/ s13311-017-0585-0 